\title{
Revista \\ Triângulo \\ ÉTICA E FORMAÇÃO: REFLEXÕES ACERCA DA RELAÇÃO \\ ENTRE A VIDA DANIFICADA E A EDUCAÇÃO ESCOLAR
}

\author{
ETHICS AND FORMATION: REFLECTIONS OF THE RELATIONSHIP \\ BETWEEN DAMAGED LIFE AND SCHOOL EDUCATION
}

Helga Peres ${ }^{1}$

\begin{abstract}
RESUMO
Frente a um panorama social onde a situação perene do sujeito contemporâneo permite que o ser humano só se reconheça no âmbito das trocas, questões ligadas ao campo da ética e da filosofia moral tomam proporções amplas e devem ser elucidadas sob o escrutínio da crítica. Desse modo, neste artigo temos o objetivo central deexplicitar alguns pontos ligados a essa temática e sua relação com o campo da educação, especificamente se levarmos em conta o parâmetrosemiformativo sobre o qual está apoiado o sistema educacional brasileiro. Tomando como aporte as reflexões de Theodor W. Adorno sobre a ética em tempos de esfacelamento da auto-consciência crítica, traremos tal discussão com base em autores que fundamentam tal obra, buscando a compreensão e a ampliação - no campo teórico - da discussão sobre as relações existentes entre ética e formação social. Destarte, a partir do diálogo entre algumas categorias destacadaspor Aristóteles e Marx, deduzimos a hipótese de que é necessário pensar em uma educação emancipatória - que tome por princípio ético a máxima "Que Auschwitz não se repita" -, onde lancemos olhos para os sujeitos, de modo que se façam as necessárias reflexões sobre o processo de rompimento com as condições objetivas que nos reificam.
\end{abstract}

Palavras-chave: Ética. Filosofia moral. Semiformação. Educação escolar. Theodor. W. Adorno.

\begin{abstract}
Considering a social landscape where the perennial situation the contemporary subject allows the human is recognized only in the context of trade, questions related to the field of ethics and the moral philosophy take ample proportions and must be elucidated under the critical scrutiny. Like this, in the article have the central aims of clarifying some points connected to this issue and its relation to the field of education, especially if we take into account the semiformative parameter on which is supported the Brazilian educational system. Taking as input the Theodor W. Adorno's reflections about the ethics in times of disintegration of critical self-awareness, we will bring the dialogue between authors that underlie this work, seeking understanding and expanding - in theory - the discussion about the relationship between ethics and social formation. Thus, based on the dialogue between the points highlighted by Aristoteles and Marx, we will deducted the hypothesis that is necessary to think of an emancipatory education - to take ethical principle by the maxim "What Auschwitz will not repeat itself" -, which let us cast eyes to the subject, so that may be the necessary reflections on the process of breaking with the objective conditions that reify us.
\end{abstract}

Keywords: Ethics. Moral philosophy. Semiformation. School education. Theodor W. Adorno.

\footnotetext{
${ }^{1}$ Faculdade de Ciências e Letras - Universidade Estadual Paulista (UNESP) Campus de Araraquara. Email: helgacperes@hotmail.com
} 
Em meio à guerra sonhava-se que, vinda a paz, a humanidade vitoriosa aplicaria sua energia liberada para criar novos valores de cultura, para imprimir à civilização um novo desenvolvimento.

A tão esperada paz chegou.

E o que vemos?

(Sergei Eisenstein, 1949)

\section{INTRODUÇÃO}

As reflexões que tangem o campo da ética não podem ser elucidadas de forma despretensiosa, visto que, enquanto sujeitos reificados, estamos envolvidos de forma intrínseca aos percalços de uma vida danificada. É necessário compreendê-la. Compreendê-la em seu esfacelamento, para que cada um de seus fragmentos faça-nos enxergar além daquilo que vemos de forma evidente e imediata. Compreendê-la em sua fragilidade, de modo que a auto-consciência de nossa condição fortaleça as possibilidades de resgate da vida como foco de resistência.

Buscaremos tecer algumas considerações que contribuam para a discussão fundamentada nesta possibilidade, considerando as concepções de alguns autores que nos trazem contribuições no campo da filosofia moral e dialogam com a obra Minima Moralia de T.W. Adorno. Pensando ainda a dimensão ética em sua relação com o campo da educação, faremos alguns apontamentos sobre essas categorias que, para além de sua relação, estão inseridas em um mesmo panorama de reificação. É nesse panorama que os sujeitos são roubados de si, para tornarem-se objetos configurados à imagem e semelhança do capital, adequados a realidade que os oprime.

Ancorada na subjetividade, essa ideologia encontrou seu lugar: "O sentido prático entre os homens que desaloja entre eles todo o ornamento ideológico, transformou-se em ideologia para tratar os homens como coisas". (ADORNO, 2001, p. 37). A objetificação alienada ganhou seu lugar, e podemos vê-la nas problemáticas que se delineiam contemporaneamente, por exemplo, no enfraquecimento da capacidade crítica dos indivíduos. Porquanto, pensar a educação nesse contexto requer olhos atentos para algo que se esvaiu: a vida auto-consciente, presentemente subsumida à lógica das relações que visam somente a adaptação àquilo que lhes é aparente.

Partindo de uma proposição negativa, buscaremos enfatizar, ainda, algumas discussões sobre a dimensão moral da educação contemporânea. É relevante considerar que, 
concomitante à desumanização dos sujeitos, é nos mesmos que encontram-se vias que demarcam a possibilidade de seu fortalecimento; para tanto, é imprescindível ir além do imediatismo, identificando suas tantas rupturas e contradições.

\section{ALGUNS APONTAMENTOS SOBRE O CONCEITO DE ÉTICA}

A melancólica ciência, da qual alguns fragmentos ofereço ao meu amigo, refere-se a um domínio que, desde tempos imemoriais, se considerou peculiar à filosofia, mas que a partir da transformação desta em método caiu no desrespeito intelectual, na arbitrariedade sentenciosa e, por fim, no esquecimento: a doutrina da vida recta. (ADORNO, 2001, p. 7).

O trecho inicial da dedicatória de Minima Moralia nos mostra o escopo que fundamentará as reflexões tecidas por T. W. Adorno ao longo dessa obra, onde busca fazer uma investigação sobre a configuração alienada do sujeito contemporâneo sob a ótica da crítica da moralidade. A doutrina da vidareta que, segundo o autor, caiu no esquecimento, é a vida caracterizada pela virtude, possuidora de um telos: a ética.

Essa ideia nos remete à Antiguidade Clássica onde Aristóteles coloca em pauta o conceito de ética, associando-o à vida política. Considerando que toda ação humana é teleológica, ou seja, visa determinados fins, Aristóteles afirma que o melhor de todos os fins é a busca pelo sumo bem, que deve ser perseguido por si mesmo, e não como um caminho para atingir outras finalidades; este está associado diretamente à vida política, pois é esta, e apenas esta, que proporcionará a autêntica felicidade, elemento primordialmente constituinte de sua ideia a respeito do bem: “Ora, como a política utiliza as demais ciências e, por outro lado, legisla sobre o que devemos e o que não devemos fazer, a finalidade dessa ciência deve abranger a das outras, de modo que essa finalidade será o bem humano". (ARISTÓTELES, 2000, p. 6).

O fim da ética, neste sentido, é contribuir para que os indivíduos conheçam a felicidade na pólis através da política. Ela terá estrita importância na configuração do ethos seus hábitos e costumes: sendo estes caracterizados por sua contingência e pelo seu potencial de modificabilidade, a ética atuará justamente no processo de transformação do homem, para que este busque e alcance a felicidade que o tornará plenamente realizado. Portanto, política e ética são indissociáveis, visto que sem a ética tornar-se-ia impossível a constituição das boas 
relações políticas no âmbito da pólis, bem como a constituição humana pautada no bom uso das virtudes.

Existem três tipos de vida: a vida agradável, ligada aos prazeres; a vida contemplativa, que identifica o bem à filosofia; e a vida política, que "[...] é o melhor dos fins, e essa ciência dedica o melhor de seus esforços a fazer com que os cidadãos sejam bons e capazes de nobres ações”. (2000, p. 21). Os homens não podem aspirar somente aquilo que vem dos deuses, em uma atividade estritamente contemplativa, bem como não podem viver enquanto reféns de suas paixões e prazeres. Por isso, na vida política é que encontrarão a realização.

Ética, política e felicidade são indissociáveis no pensamento de Aristóteles. A felicidade está ligada diretamente ao âmbito das ações ético-políticas no processo de autoconstituição do ser humano. Ela se dá no âmbito da práxis: meios e fins possuem relação entre si, de modo que os indivíduos cumpram a função e o propósito a que se destinam; deste modo, pode-se dizer que a felicidade está ligada a uma ação prático-reflexiva, o que a coloca como atividade que está em consonância com os princípios de uma "vida reta".

A vida reta diz respeito a utilização da razão de forma autônoma, e fazê-lo adquire, nessa discussão, uma significação primordial. Os sujeitos devem possuir a capacidade de refletir sobre suas ações, ao mesmo tempo em que as executam; isso implica a capacidade de fazer escolhas, de efetivar suas ações de modo deliberativo. Para que o ser humano se torne verdadeiramente humano, buscando na política a possibilidade de alcançar o verdadeiro bem, a vida reta deve ter conformidade com esta razão reta, ou seja: a finalidade da ação e a própria ação devem ser indissociáveis.

Da mesma forma as paixões e vontades devem estar submetidas à razão deliberativa. O homem controlado por suas paixões é o mesmo que buscará impor suas vontades à outrem, de modo que a submissão acarretaria o rompimento entre finalidade e ação. Estritamente ligada à vida política, a ética se relacionará diretamente com o ethos nos desvendando um certo princípio pedagógico, no sentido de que os sujeitos devem educar seus hábitos em função da temperança - critério para que alcancem a virtude que levará à felicidade. A educação do ethos deve estar direcionada para ações deliberativas e autônomas, guiadas por uma razão que dê vazão à efetivação de ações voltadas para a pólis, buscando o sumo bem.

Sobre as ideias acerca da ética e da razão pautada nas concepções de Aristóteles, Adorno afirma que 
O que outrora para os filósofos se chamou vida converteu-se na esfera do privado e, em seguida, apenas do consumo, a qual, como apêndice do processo material da produção, se arrasta com este sem autonomia e sem substância própria. Quem quiser experimentar a verdade sobre a vida imediata deve indagar sua forma alienada, os poderes objectivos que determinam, até ao mais recôndito, a existência individual. [...] a relação entre a vida e a produção, que degrada efectivamente aquela a um fenómeno efémero desta, é de todo absurda. Invertem-se entre si o meio e o fim. (2001, p.7)

O diagnóstico feito por Adorno nos indica a direção de suas reflexões. Para além de um princípio ético voltado para o sujeito centrado na vida política, condições objetivas degradadas transfiguram essa perspectiva. É importante lembrar que, nos processos de sociabilidade capitalista, o homem adquire função de apêndice do processo que ocorre entre as mercadorias; portanto, seu telos é a representação ampliada do valor das mesmas. "A riqueza das sociedades em que domina o modo de produção capitalista aparece como uma “imensa coleção de mercadorias"” (MARX, 1999, p. 165) e, neste sentido, a roupagem das trocas adquire papel central para as formas de sociabilidade.

Para desvelar os mecanismos que nos permitem compreender a situação perene do sujeito contemporâneo, onde o ser humano só se reconhece no âmbito das trocas, é preciso entender algumas categorias discutidas por Marx (1999). A partir de uma análise que avança através de mediações, visando descrever as categorias supracitadas a partir de um determinado tempo histórico, o autor propõe a ideia de trabalho social enquanto uma relação metabólica entre homem e natureza; ao atuar sobre esta, o homem a modifica e modifica a si próprio, ao mesmo tempo em que se apropria historicamente daquilo que foi produzido por gerações anteriores. O trabalho social se caracteriza, portanto, como uma atividade teleológica que se constitui como uma condição constante e eterna do ser humano.

O modo de produção capitalista, no entanto, acarreta uma nova concepção acerca do trabalho, onde este se converte em trabalho alienado: o produto passa a confrontar o trabalhador, de forma que o estranhamento não permite que esse se reconheça naquilo que produziu. Proveniente do trabalho social, a mercadoria adquire aqui papel fundamental:

Uma mercadoria tem um valor por ser uma cristalização de um trabalho social. A grandeza de seu valor, ou seu valor relativo, depende da maior ou menor quantidade dessa substância social que ela encerra, quer dizer, da quantidade relativa de trabalho necessário à sua produção. Portanto, os valores relativos das mercadorias se 
determinam pelas correspondentes quantidades ou somas de trabalho invertidas, realizadas, plasmadas nelas. (MARX, 1999, p. 92)

Considerando que o ser humano, no presente contexto, só se reconhece no âmbito das trocas, a mercadoria, entidade puramente material, adentra este processo em uma linha tênue. A troca causa uma transfiguração na mercadoria - ressaltando o caráter de equivalência do trabalho morto, de modo que não se perceba a quantidade de trabalho consubstanciado que há no objeto. A mercadoria também é possuidora de carências e necessidades. Inverte-se o processo onde esta satisfaria as necessidades humanas: é imperativo para a mercadoria ser trocada, e as necessidades humanas tornam-se meio para este fim, para a efetivação de seus níveis de abstração. (MARX, 1999). Portanto, se o telos humano torna-se meio, há uma relação coisificada, caracterizando o fetiche da mercadoria, que consiste no encobrimento do processo social entre seres humanos pela realidade material da relação social entre mercadorias.

É importante compreender esse processo, visto que o mesmo produz novas condições objetivas e, consequentemente, mudanças também para o âmbito da subjetividade. Em meio às contradições que inundam todos os tipos de relações que se efetivam neste contexto, pensar a liberdade e a razão - aos parâmetros da razão reta de Aristóteles - como pertencentes ao indivíduo e direcionadas à vida política é uma possibilidade que encontra-se esfacelada, visto que a relação entre meios e fins transfigurou-se no âmbito das relações de troca.

Ao contrário de uma efetiva liberdade, sob a ótica marxista, é possível pensar a existência de um potencial de liberdade enquanto ferramenta política. Só haverá lugar para este caso exista uma práxis política que parta diretamente da classe operária, pois somente esta possui interesse na universalidade, em deixar de lado interesses particulares. Portanto, considerando a ausência de liberdade e razão autônomas, não se pode falar em moral ou ética em um sentido efetivo. O sujeito está alienado de si, suprimido por uma totalidade que o toma por engrenagem. A ética está no campo do vir-a-ser: a possibilidade de uma conduta ética que traga aos sujeitos a capacidade de usar livremente sua própria razão de forma autônoma depende de uma práxis revolucionária, que supere o modo de produção capitalista.

Após a crítica marxista torna-se impossível refletir sobre ética num sentido positivo; é partindo de uma proposição negativa - buscando a superação das rupturas e contradições no próprio objeto - que T. W. Adorno analisará o declínio de uma vida auto-consciente, mediada por condições objetivas pautadas na sedimentação do capital. O tom de sua análise nos mostra que, lançando olhos para a configuração do indivíduo, é necessário subsidiar uma reflexão 
pautada na crítica que denuncia os consequentes malefícios ocasionados aos sujeitos. Enfatizando o que já foi dito, "Quem quiser experimentar a verdade sobre a vida imediata deve indagar sua forma alienada, os poderes objectivos que determinam, até ao mais recôndito, a existência individual”. (ADORNO, 2001, p. 7).

Acerca da constituição alienada dos indivíduos, é necessário o retorno à filosofia para compreender as tendências e transformações ocasionadas pela supremacia do capital, que traz uma nova configuração para aquilo que entendemos por razão: não nos destinamos, neste trabalho, a fazer uma análise pormenorizada desse conceito. Faz-se necessário, no entanto, compreender que, no modo de produção capitalista desenvolveu-se e efetivou-se uma razão estritamente instrumental - concebida enquanto ratio -, uma racionalidade estreita, que sempre esteve contida na razão humana e que renuncia à própria reflexão. A “ratio torna-se irrational [...] quando hipostasia suas produções, as abstrações, contra o sentido do pensamento". (ADORNO, 2009, p. 37)

Trata-se de uma razão que se coloca a serviço do mercado; o altíssimo grau de desenvolvimento desta culmina em atos desvelados por parte de indivíduos. A razão se identifica com determinados aspectos de uma cultura que legitima produtos voltados justamente para essa lógica, corroborando com o que se pode chamar de irracionalidade:

O irracionalismo que se denuncia nessas reconstruções vazias está muito longe de resistir à ratio industrial. [...] Ele limita, é verdade, a fria razão em proveito da vida imediata, convertendo, porém, a vida num princípio hostil ao pensamento. Sob a aparência dessa hostilidade, o sentimento e, no final das contas, toda expressão humana e, inclusive, a cultura em geral são subtraídos à responsabilidade perante o pensamento, mas por isso mesmo se transformam no elemento neutralizado da ratio universal do sistema económico que há muito se tornou irracional. (ADORNO, 1985, p. 55)

Tem-se a priorização de um caráter instrumental dessa razão em detrimento de sua dimensão emancipatória e autônoma. Por intermédio da Indústria Cultural ${ }^{1}$ os indivíduos, tidos como objetos, se sentem participantes de uma realidade na qual a satisfação se conquista através da mercadoria, o que faz com que deixem de lado sua individuação em prol de uma adaptação social que coloca o todo sobre a parte, que deduz aquilo que é particular do universal em

função de uma ideologia voltada explicitamente para tal função. 
Incapazes de efetivar qualquer experiência que se distancie ou que não seja mediada pela ratio, os sujeitos - não mais sujeitos de si - são impedidos de lançarem mão de sua situação, na medida em que se fixam, de formas cada vez mais arraigadas, tendências voltadas para a dominação e para a barbárie. Os novos valores de cultura e o desenvolvimento técnico acabam por levar a caminhos que, outrora, culminaram em episódios abissais como os campos de concentração e outros tantos genocídios justificados pelo "bom uso da razão": "Nos movimentos que as máquinas exigem daqueles que as utilizam reside já o violento, o brutal e o constante atropelo dos maus-tratos fascistas". (ADORNO, 2001, p. 35).

Como pensar em uma ação ética, predominantemente autônoma, em condições objetivas denigridas? De que forma resgatar uma moralidade que desconstrua nossa suposta segurança e que nos torne verdadeiramente humanos? Adorno (2001) nos responde que é necessário desvelar,no plano subjetivo, todas as perspectivas de uma objetividade alienada; a partir daí, tornar-se-á possível apontar formas de resistência, que encontram-se no próprio sujeito. Embora viva uma vida danificada, violentamente tomada de si em função do capital; embora sua constituição interna e suas funções psíquicas funcionem em princípio de identificação com os processos produtivos, há ainda algo da vida que persiste: esse algo encontra-se na possibilidade de que percebamos o engodo a qual estamos submetidos. Contudo, trata-se de uma possibilidade ainda frágil, visto que o presente modo de produção engloba também essas brechas.

Essa fragilidade estende-se também para os sujeitos: sua condição moral deveria ser absolutamente frágil e insegura. Quando se está adaptado, no entanto, em consonância com o que está imposto, não há margem para que a consciência dessa condição venha a tona, por isso a ausência da moralidade reside justamente na carência da mesma. Porquanto a moralidade só é possível na compreensão da auto-fragilidade, visto que a recusa de todos os sofrimentos e desprazeres acaba por gerar o endurecimento e a frieza dos sujeitos.

Contudo, é necessário pensar a existência de uma suposta "moral" contemporânea. No contexto da sociabilidade burguesa, os padrões normativos únicos tornam-se obsoletos de modo que diversas modalidades de verdade podem ser admitidas a partir de então. A pretensão de uma única lei moral se esvai, trazendo, para a modernidade, um paradoxo: ao mesmo tempo em que a pluralidade moral encontrou seu lugar, caracterizando uma forma de liberdade, há a fabricação de modelos morais padronizados, dos quais é impossível que os indivíduos passem ilesos. 
Em tempos de diversos modelos morais, os sujeitos encontram sempre seu lugar dentro de um determinado modelo, não havendo, portanto, o mal-estar ocasionado pela repressão - presentemente obsoleta. Considerando que, contemporaneamente o principal modelo moral de que deveríamos ter ciência traz a identificação entre consumo e gratificação, a lei passa a ser contrária à repressão; ela não mais reprime os sujeitos, mas os incita a gozarem incessantemente, em um processo associado à dessublimação repressiva. A falta de reconhecimento do sofrimento torna-se um mecanismo de dominação, onde o intuito do mercado é o ajustamento dos sujeitos a essa ilusória felicidade.

É próprio do mecanismo de dominação impedir o conhecimento do sofrimento que provoca, e há um caminho directo desde o evangelho da alegria de viver até à instalação de matadouros humanos, embora estes estejam, como na Polónia, tão distantes que cada um dos seus habitantes se pode convencer de que não houve os gritos de dor. Eis o esquema da imperturbada capacidade de gozo. (ADORNO, 2001, p. $60)$

Se os mecanismos de dominação atuam no sentido de suprimir qualquer contato efetivo com as condições que nos fazem enxergar aquilo que há de verdadeiramente humano em cada sujeito, o papel da educação encontra-se no limiar das ambiguidades que a cercam. Pensar em uma educação voltada ao desvelamento das ideologias responsáveis por uma vida "cega" é pensar também uma educação que está inserida em um panorama onde as supostas instâncias moralizantes supracitadas encontram terreno fértil.

“Que Auschwitz não se repita" - imperativo que, no pensamento adorniano, expressa o entrelaçamento entre educação e ética. Buscaremos, nas conclusões que se seguem, tecer algumas ideias acerca do significado adquirido por essas palavras, que exprimem não apenas os aspectos de uma História obscurecida por acontecimentos que remetem à barbárie mas, também, à todas as perspectivas de emancipação dos sujeitos.

\section{CONCLUSÕES: PELA BUSCA DE UMA EDUCAÇÃO NÃO REIFICADA}

A busca por uma educação voltada para a emancipação está justamente na compreensão do caráter fetichizado da Formação Social, visto que a mesma encontra-se convertida em semiformação. Nas palavras de Adorno (2010), “A formação cultural agora se converte em uma semiformação socializada, na onipresença do espírito alienado, que, 
segundo sua gênese e seu sentido, não antecede à formação cultural, mas a sucede. Desse modo, tudo fica aprisionado nas malhas da socialização". (p. 9).

Sob a ótica adorniana, aquilo que deveria haver de humano nos sujeitos lhes é retirado em função da perpetuação da estrutura de classes. O divórcio entre cultura e práxis os mantém em estado de inércia. Constitui-se, dessa forma, a totalidade do processo de semiformação, que dirime a possibilidade de uma real autonomia dos sujeitos, sendo esta intrínseca à reflexão e auto-consciência necessárias a uma formação social emancipatória. $\mathrm{O}$ enfraquecimento das capacidades autônomas é associado à totalidade denegrida, em função de um panorama objetivo que corrobora com a debilidade da formação.

É importante ter em mente que, atuando no sentido da semiformação, as propostas pedagógicas contemporâneas estão atreladas às demandas sociais, buscando a formação de sujeitos adaptados à fragmentação de uma vida voltada para o fortalecimento da ratio e para a legitimação de ideologias pautadas em relações de troca. Essas propostas mostram-se cada vez mais cúmplices de uma formação educacional heterônoma, a fim de que as novas gerações continuem sustentando, através das relações no âmbito do capital, os produtos fornecidos pela Indústria Cultural.

Intensifica-se, assim, no âmbito da formação educacional escolar, o desenvolvimento da semiformação: se esta "é uma fraqueza em relação ao tempo, à memória, única mediação capaz de fazer na consciência aquela síntese da experiência que caracterizou a formação cultural em outros tempos". (ADORNO, 2010, p. 33), a formação escolar deveria preocuparse em desenvolver essas funções; não obstante, efetiva-se o processo contrário através do vínculo arraigado, que se torna cada vez mais estável, com a suposta moral anteriormente referida.

Diferente de Marx, que propõe a supressão do modo de produção capitalista através de uma revolução que parta da classe operária, Adorno enfatiza que a mesma perdeu o seu momento, encontrando-se além do nosso alcance. Contudo, enxerga que não há possibilidade de emancipação caso se perpetuem as presentes condições objetivas, que denigrem a individualidade e a subjetividade dos sujeitos, bem como as instâncias formativas: a possibilidade do fortalecimento dos sujeitos a partir da elaboração de todos os sofrimentos vividos, de forma que o mesmo aprenda a lidar conscientemente com o seu passado, detém uma chave para que as tendências à barbárie sejam minimizadas.

Reelaborar o passado adquire, para esse processo de fortalecimento, a importância de trazer a tona todos os fragmentos dos contrassensos que se encontram ainda vivos no presente. 
Isso significa a necessidade de uma relação dinâmica com a cultura, de modo que se constitua a auto-consciência voltada para a profunda compreensão e vivacidade:

É preciso buscar as raízes nos perseguidores e não nas vítimas, assassinadas sob os pretextos mais mesquinhos. Torna-se necessário o que a esse respeito denominei de inflexão em direção ao sujeito. É preciso reconhecer os mecanismos que tornam as pessoas capazes de cometer tais atos, é preciso revelar tais mecanismos a eles próprios, procurando impedir que se tornem novamente capazes de tais atos, na medida em que se desperta uma consciência geral acerca desses mecanismos. [...] É necessário contrapor-se a uma tal ausência de consciência, é preciso evitar que as pessoas golpeiem para os lados sem refletir a respeito de si próprias. A educação tem sentido unicamente como educação dirigida a uma auto-reflexão crítica. (ADORNO, 1995, p. 120)

Uma educação voltada para a "auto-reflexão crítica" nos traz o significado de que a formação deve ir além da mera transmissão de conteúdos que, por si só, não é suficiente para que todos os processos sociais que culminaram em Auschwitz não se repitam. Deve ir além da reprodução dos elementos da barbárie que se fazem ainda presentes. Deve ir além da mera educação para a adaptação às condições objetivas que se fazem avassaladoras.

É preciso, para uma educação que tenha como telos "Que Auschwitz não se repita", a retomada de um princípio ético voltado para a recuperação da razão historicamente construída, em detrimento da ratio. Para Adorno, o enfraquecimento das capacidades críticas dos indivíduos consiste em um problema moral: a construção de um processo educativo emancipatório orientado para a autonomia tomará corpo assim que a solução para essa problemática for encontrada. Essa solução se dá através da consciência de nossa própria fragilidade, para que torne-se possível acolher as fraquezas de outrem; é preciso que a autoconsciência nos faça enxergar as contradições que tangem essa fragilidade, de modo que nos reconheçamos enquanto humanos inseridos em um contexto paradoxal, onde as forças ideológicas reprimem as possibilidades de reflexão.

"A única concretização efetiva da emancipação consiste em que aquelas poucas pessoas interessadas nesta direção orientem toda a sua energia para que a educação seja uma educação para a contestação e para a resistência”. (MAAR, 1995, p. 38). Pensar em uma educação emancipatória requer que lancemos olhos para os sujeitos, de modo que se façam possíveis as fraturas necessárias para o rompimento com as condições objetivas que nos reificam. 
Frente ao que foi exposto, chegamos aos questionamentos e às problemáticas aos quais pretendíamos nesse trabalho; diante de questões tão paradoxais relativas a uma instância educacional que legitima a ideia de que "somos objetos e não sujeitos de nossas ações" (ZUIN, 2003, p. 141), faz-se necessária a crítica, julgando que "é por meio dela e do que se pode distinguir, escolher, julgar e apreciar por um processo de decisão que eles nos ensinaram a colocar em suspenso, sub judice, qualquer julgamento sobre o mundo, incluindo aí o próprio pensamento que se elabora para dar conta deste". (SOARES, 2002, p. 11).

É em contraposição a esta ausência de julgamento que se direcionam nossas reflexões; as problemáticas da sociedade contemporânea devem ser desveladas, principalmente por estarmos, inevitavelmente, imersos em um mar de percalços que cegam nosso discernimento. Porquanto, propomos tal reflexão a partir da crítica, porém uma crítica que tome como base fundamentos teóricos apoiados no reconhecimento de uma realidade que deve ser criticada a partir dela e para além dela.

NOTA

1. O conceito de Indústria Cultural foi cunhado por Theodor W. Adorno e Max Horkheimer em Dialética do Esclarecimento (Dialektik der Aufkärung); a obra foi publicada originalmente em 1947, em Amsterdã. Os autores utilizam o conceito de Indústria Cultural em substituição ao termo cultura de massas, pois este alude a ideia de uma cultura provinda espontaneamente das massas, quando, na verdade, as massas são manipuladas pelo que é produzido e legitimado pelo poder hegemônico da Indústria Cultural.

\section{REFERÊNCIAS}

ADORNO, T.W. Educação e emancipação. Trad. Wolfgang Leo Maar. Rio de Janeiro: Paz e Terra, $1995 \mathrm{~d}$.

. Teoria da semiformação. Trad. Newton Ramos de Oliveira. In: PUCCI, B.; ZUIN, A. A. S.; LASTÓRIA, L. A. C. N. (Orgs.) Teoria crítica e inconformismo: novas perspectivas de pesquisa. Campinas: Autores Associados, 2010, p. 7-41 (Coleção Educação Contemporânea)

. Minima Moralia. Lisboa: Edições 70, 2001.

. Dialética Negativa. Lisboa: Edições 70, 2009.

ADORNO, T. W.; HORKHEIMER, M. Dialética do Esclarecimento. Tradução: Guido Antônio de Almeida. Rio de Janeiro: Jorge Zahar Editora, 1985. 
ARISTÓTELES. Ética a Nicômaco. São Paulo: Nova Cultural, 2000.

MAAR, W. Prefácio. In: ADORNO, T.W. Educação e Emancipação. Trad. Wolfgang Leo Maar. Rio de Janeiro: Paz e Terra, 1995d.

MARX, K. O capital: crítica da economia política. São Paulo: Nova Cultural, 1988.

SOARES, J.C. Apresentação à edição brasileira: a "imaginação dialética" de Rolf Wiggershaus. In: WIGGERSHAUS, R. A Escola de Frankfurt: história, desenvolvimento teórico, significação política. Rio de Janeiro: DIFEL, 2002, p. 9-12.

ZUIN, A.A.S. A sociedade do espetáculo e o simulacro da experiência formativa. In: LASTÓRIA, L.A.C.N.; COSTA, B.C.G.; PUCCI, B. (Org.) Tecnologia, Cultura e Formação... ainda Auschwitz. SP: Cortez, 2003, p. 141-157.

RECEBIDO EM: 13/03/2015.

APROVADO EM: 21/09/2015. 